\title{
The development of EMPD model for identifying and predicting the materials' moisture performances
}

\author{
Yumeng Cui ${ }^{1}$, Yufeng Zhang ${ }^{1, *}$, Huihui Zhao ${ }^{1}$, and Xue Lin $^{1}$ \\ ${ }^{1}$ State Key Laboratory of Subtropical Building Science, Department of Architecture, South China University of Technology, Guangzhou, \\ China
}

\begin{abstract}
Moisture excess or lack in buildings has many adverse effects on human health, structural durability and building energy consumption, and moisture design for building materials is an important and efficient measurement for creating a stable indoor climate. However, the current quick test method (e.g., moisture buffer value test) can only evaluate the materials' moisture buffering abilities roughly, and the advanced numerical prediction method (e.g., using HAM models) is hardly applicable in practices due to insufficient materials' hygrothermal properties and its long computing time. EMPD model can calculate with less input parameters and short time without sacrificing accuracy. While this paper found existing EMPD has limited application conditions, and further proposed modified multilayer EMPD model. A new approach can be applied to identify and predict the moisture performances of building materials. In this paper, two typical building materials with diverse hygric properties were simulated. Their key parameters of the modified model was easily inversed by a $24 \mathrm{~h}$ standard box test instead of several months of material hygrothermal properties tests, based on which, the materials' actual performances under various conditions can be predicted. The presented approach was validated by comparing the numerical predictions with HAM results in the corresponding conditions. This study provides an easy and fast way to test and predict the moisture performances of building materials and indoor moisture in practices.
\end{abstract}

\section{Introduction}

Interior humidity, as an essential factor of indoor environment, has substantial influences on human comfort $[1,2]$ and health [3, 4], component durability [5] and building energy [6] Humidity-related problems frequently occur in buildings, due to the poor moisture design of materials and buildings, and the lack of humidity control of HVAC systems. A recent useful exploration is to damp the indoor humidity variations through the interaction between HVAC systems and building moisture buffering. The reliable and feasible method to identify and predict the materials' moisture performance in real building conditions is essential for such efforts.

The Moisture Buffering Value (MBV) test method proposed by the Nordtest project [7] is an optional method. It is operated under the standard condition of square-wave relative humidity $(\mathrm{RH})$ change, and the moisture ad/desorption performances of the test materials are estimated by the derived MBV and the real RH conditions. However, it assumes that the mass of moisture buffering of the materials is in equilibrium with the room humidity, which can cause fail prediction of the exact course of the indoor RH-variations in reality [8].

Currently, there are three well-known models predicting moisture performances of materials and buildings: The Effective Capacitance (EC) model, the Heat, Air and Moisture Transfer (HAM) model, and the Effective
Moisture Penetration Depth (EMPD) model. The EC model is less accurate due to its empirical EC value [9]. The HAM model [10], as a detailed finite-difference approach for the problems coupled heat, moisture and liquid water transfers, has superior precision and acts as criterion to test others. Nevertheless, due to the long computational time [11] (usually 100-1000 times than others) and the numerous and complicated inputs (usually from 2-6 months of tests), the HAM model is hardly applicable in engineering practices.

The EMPD model, firstly proposed by Cunningham [12], assumes the transferred moisture is exchanged between a fictitious moisture penetration layer and zone air. It is suitable for engineering applications, especially in the early design stage, through a good trade-off between prediction precision and computational speed. The original EMPD model is one-layer and for short-term (24h) RH fluctuation, and based on which, a two-layer model [13] is proposed for both short-term and long-term (2-3 weeks) $\mathrm{RH}$ changes by taking the surface and deep layers into account.

Although the input parameters are much less for the EMPD model compared to those of the HAM model, a big obstacle still exists in achieving them, especially for the hygrothermal properties. The material property database $[14,15]$ has nowadays been enriched greatly, however, it is hard to develop and updated the database due to the long time and complicated testing of the hygrothermal 
properties [16], especially for those ceaseless new materials. To solve the problem, Woods and Winkler [17, 18 ] proposed and derived inverse parameters by reaching the numerical agreement between the EMPD model prediction and the test results. The validity of such approach under the real conditions other than the test ones is however not confirmed. An alternative way proposed by Janssen [8] and Vereecken [19] is to inversely obtain the parameters to be used in the EMPD model instead of the materials' hygric properties. This can avoid introducing assumptions and has good potentials to apply in various scenarios. The solution greatly improves the engineering applicability of EMPD model.

The purpose of this paper is to propose an efficient approach to identify and predict the moisture performances of building materials based on the EMPD model. The specific contents are: 1) to propose a modified EMPD model based on the existing one-layer model, 2) to conduct numerical experiments on the moisture performances of typical building materials under the standard and real building conditions, 3) to obtain the key parameters of the EMPD model by using the inverse method, and finally, 4) to verify the effectiveness of the proposed model. This study provides the base of the practical approach to identify and predict the materials' moisture performance in real building conditions, and potentially contributes to moisture design, HVAC control and built environment improvement.

\section{A Modified Multilayer EMPD Model Based on the Existing One-layer Model}

In this section, a modified multilayer EMPD model is proposed to consider short-term moisture production based on the existing one-layer EMPD model in ref. [12].

\subsection{The Existing one-layer EMPD model}

The moisture balance for the room air can be written as:

$$
\frac{V}{R_{v} T_{i}} \cdot \frac{d p_{v i}}{d t}=\left(p_{v e}-p_{v i}\right) \frac{n V}{3600 R_{V} T_{i}}+G_{v p}-G_{b u f}
$$

The existing EMPD can be shown as Fig.1.

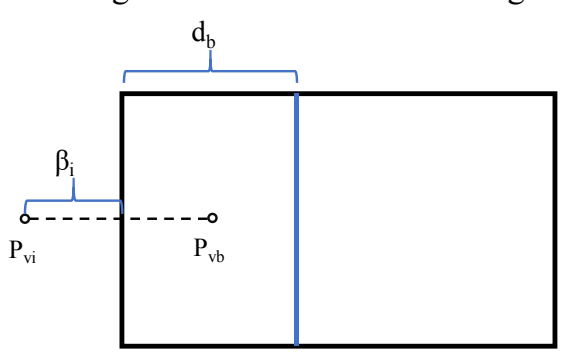

Fig. 1 Schematic Diagrams of Existing EMPD Model

It is written as:

$$
\begin{gathered}
G_{b u f}=A \cdot \frac{p_{v i}-p_{v b}}{\frac{1}{\beta_{i}}+\frac{d_{b}}{2 \cdot \delta_{p}}}=A \cdot \zeta \cdot d_{b} \cdot \frac{\partial}{\partial t}\left(\frac{p_{v b}}{p_{v, s a t}\left(\theta_{b}\right)}\right) \\
d_{b}=a \cdot d_{E M P D, 1 / e}=a \cdot \sqrt{\frac{\delta_{p} t_{p} p_{s a t}\left(\theta_{b}\right)}{\zeta \cdot \pi}} \quad a=\min \left(\frac{d}{d_{E M P D}}, 1\right)
\end{gathered}
$$

$$
b_{m}=\sqrt{\frac{\delta_{p} \cdot \zeta}{p_{s a t}}}
$$

In combination with (3)-(4), the equation (2) can be rewritten as:

$$
\frac{\partial p_{v b}}{\partial t}=\frac{p_{v i}-p_{v b}}{\frac{a \cdot b_{m}}{\beta_{i}}+\frac{a \cdot \sqrt{t_{p} / \pi}}{2 \cdot b_{m}}}
$$

This existing one-layer EMPD model considers both the inside moisture transfer resistance of material and surface transfer resistance and assumes the deeper parts of the materials don't take account into moisture transfer. It is proposed based on a sine-wave moisture fluctuation which includes a continuous sufficient adsorption and desorption cycle. The one-layer model is usually applied to calculate the short-term daily moisture fluctuation.

\subsection{The Modified Multilayer EMPD model}

For a regular sine-wave moisture scheme, moisture penetration only occurs in the surface effective depth layer which adsorb and desorb the moisture in one cycle. In theory, the humidity of the surface layer will return to the initial conditions at the end of a period. So, there is no moisture penetration though the deeper parts. However, this simplified assumption is not always reasonable for the daily moisture fluctuation from moisture production and ventilation. The desorption process is not sufficient due to limited ventilation time or the increase of the outdoor humidity. That means it is hard to determine actual cycling time in reality. Besides, in this process, the deeper parts will absorb moisture from the surface layer. So, it is still necessary to divide the materials into multilayer to consider the moisture transfer of deeper layer in the daily short-term moisture fluctuation.

The new multilayer EMPD model derives from multicontrol-volume thought, shown as Fig.2. In theory, the more layers are, the higher the accuracy is.

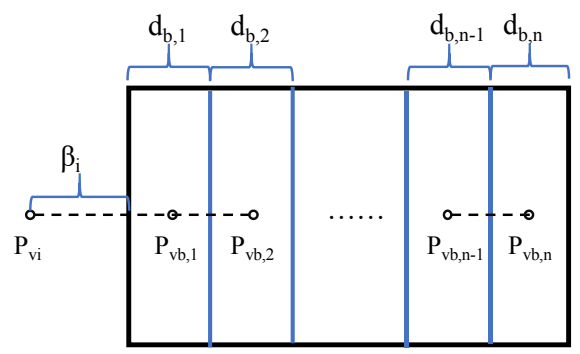

Fig. 2 The Modified Multilayer EMPD Model

The number of divided layers can be chosen by both the specified accuracy and calculation complexity. Through our calculation, the division of three layers is relatively reasonable. The three-control-volume equations can be written as:

$$
\begin{gathered}
A \cdot \frac{p_{v i}-p_{v b, 1}}{\frac{1}{\beta_{i}}+\frac{d_{b, 1}}{2 \cdot \delta_{p}}}+A \cdot \frac{p_{v b, 2}-p_{v b, 1}}{\frac{d_{b, 1}}{2 \cdot \delta_{p}}+\frac{d_{b, 2}}{2 \cdot \delta_{p}}}=A \cdot \xi \cdot d_{b, 1} \cdot \frac{\partial}{\partial t}\left(\frac{p_{v b, 1}}{p_{v, s a t}\left(\theta_{b}\right)}\right) \\
d_{b, 1}=a \cdot d_{E M P D, 1}=a \cdot \sqrt{\frac{\delta_{p} t_{p, 1} p_{s a t}\left(\theta_{b}\right)}{\xi \cdot \pi}}
\end{gathered}
$$




$$
\begin{gathered}
A \cdot \frac{p_{v b, 1}-p_{v b, 2}}{\frac{d_{b, 1}}{2 \cdot \delta_{p}}+\frac{d_{b, 2}}{2 \cdot \delta_{p}}}+A \cdot \frac{p_{v b, 3}-p_{v b, 2}}{\frac{d_{b, 2}}{2 \cdot \delta_{p}}+\frac{d_{b, 3}}{2 \cdot \delta_{p}}}=A \cdot \xi \cdot d_{b, 2} \cdot \frac{\partial}{\partial t}\left(\frac{p_{v b, 2}}{p_{v, s a t}\left(\theta_{b}\right)}\right) \\
d_{b, 2}=a \cdot d_{E M P D, 2}=a \cdot \sqrt{\frac{\delta_{p} t_{p, 2} p_{s a t}\left(\theta_{b}\right)}{\xi \cdot \pi}} \\
A \cdot \frac{p_{v b, 2}-p_{v b, 3}}{\frac{d_{b, 2}}{2 \cdot \delta_{p}}+\frac{d_{b, 3}}{2 \cdot \delta_{p}}}=A \cdot \xi \cdot d_{b, 3} \cdot \frac{\partial}{\partial t}\left(\frac{p_{v b, 3}}{p_{v, s a t}\left(\theta_{b}\right)}\right) \\
d_{b, 3}=a \cdot d_{E M P D, 3}=a \cdot \sqrt{\frac{\delta_{p} t_{p, 3} p_{s a t}\left(\theta_{b}\right)}{\xi \cdot \pi}}
\end{gathered}
$$

The equations (7)-(12) can be rewritten as:

$$
\begin{aligned}
& \frac{\partial p_{v b, 1}}{\partial t}=\frac{p_{v i}-p_{v b, 1}}{\frac{a \cdot b_{m}}{\beta_{i}} \cdot \sqrt{\frac{t_{p 1}}{\pi}}+\frac{a^{2}}{2} \cdot \frac{t_{p 1}}{\pi}}+\frac{p_{v b, 2}-p_{v b, 1}}{\frac{a^{2}}{2} \cdot \frac{t_{p 1}}{\pi}+\frac{a^{2}}{2} \cdot \frac{\sqrt{t_{p 2} \cdot t_{p 1}}}{\pi}} \\
& \frac{\partial p_{v b, 2}}{\partial t}=\frac{p_{v b, 1}-p_{v b, 2}}{\frac{a^{2}}{2} \cdot \frac{\sqrt{t_{p 2} \cdot t_{p 1}}}{\pi}+\frac{a^{2}}{2} \cdot \frac{t_{p 2}}{\pi}}+\frac{p_{v b, 3}-p_{v b, 2}}{\frac{a^{2}}{2} \cdot \frac{t_{p 2}}{\pi}+\frac{a^{2}}{2} \cdot \frac{\sqrt{t_{p 2} \cdot t_{p 3}}}{\pi}}
\end{aligned}
$$
cement mortar, with diverse hygric properties were studied. Their physical properties are shown in Table 1. Some

\begin{tabular}{|c|c|c|c|c|c|c|c|c|c|c|c|c|c|c|c|c|c|c|c|c|}
\hline \multirow{4}{*}{ Material } & \multirow{2}{*}{$\begin{array}{l}\text { Thi } \\
\text { ckn } \\
\text { ess } \\
\text { d }\end{array}$} & \multirow{2}{*}{$\begin{array}{c}\text { Densit } \\
y \\
\rho\end{array}$} & \multicolumn{3}{|c|}{$\begin{array}{l}\text { Moisture } \\
\text { capacity }\end{array}$} & \multicolumn{3}{|c|}{$\begin{array}{l}\text { Resistance } \\
\text { coefficient }\end{array}$} & \multicolumn{3}{|c|}{$\begin{array}{l}\text { Hygric } \\
\text { diffusion }\end{array}$} & \multicolumn{3}{|c|}{$\begin{array}{l}\text { Hygric } \\
\text { effusivity }\end{array}$} & \multicolumn{3}{|c|}{$\begin{array}{l}\text { Effective } \\
\text { moisture } \\
\text { penetration } \\
\text { depth }\end{array}$} & \multicolumn{3}{|c|}{$\begin{array}{l}\text { Adjustment } \\
\text { factor of the } \\
\text { existing } \\
\text { EMPD model }\end{array}$} \\
\hline & & & \multicolumn{3}{|c|}{$\zeta$} & \multicolumn{3}{|c|}{$\mu$} & \multicolumn{3}{|c|}{$\mathrm{D}_{\mathrm{w}}\left(\times 10^{-9}\right)$} & \multicolumn{3}{|c|}{$b_{\mathrm{m}}\left(\times 10^{-7}\right)$} & \multicolumn{3}{|c|}{$\mathrm{d}_{\mathrm{EMPD}, 1 / \mathrm{e}}$} & \multicolumn{3}{|c|}{$\mathrm{a}$} \\
\hline & \multirow{2}{*}{$\mathrm{cm}$} & \multirow{2}{*}{$\mathrm{kg} / \mathrm{m}^{3}$} & \multicolumn{3}{|c|}{$\mathrm{kg} / \mathrm{m}^{3}$} & \multicolumn{3}{|c|}{ - } & \multicolumn{3}{|c|}{$\mathrm{m}^{2} / \mathrm{s}$} & \multicolumn{3}{|c|}{$\mathrm{kg} /\left(\mathrm{m}^{2} \cdot \mathrm{Pa} \cdot \mathrm{s}^{0.5}\right.$} & \multicolumn{3}{|c|}{$\mathrm{cm}$} & \multicolumn{3}{|c|}{ - } \\
\hline & & & $\begin{array}{l}55 \\
\% \\
\end{array}$ & $\begin{array}{l}70 \\
\%\end{array}$ & $\begin{array}{l}85 \\
\%\end{array}$ & $\begin{array}{l}55 \\
\%\end{array}$ & $\begin{array}{l}70 \\
\%\end{array}$ & $\begin{array}{l}85 \\
\%\end{array}$ & $\begin{array}{l}55 \\
\%\end{array}$ & $\begin{array}{l}70 \\
\%\end{array}$ & $\begin{array}{l}85 \\
\% \\
\end{array}$ & $\begin{array}{l}55 \\
\%\end{array}$ & $\begin{array}{l}70 \\
\%\end{array}$ & $\begin{array}{l}85 \\
\% \\
\end{array}$ & $\begin{array}{l}55 \\
\%\end{array}$ & $\begin{array}{l}70 \\
\%\end{array}$ & $\begin{array}{l}85 \\
\% \\
\end{array}$ & $\begin{array}{l}55 \\
\%\end{array}$ & $\begin{array}{l}70 \\
\%\end{array}$ & $\begin{array}{l}85 \\
\%\end{array}$ \\
\hline $\begin{array}{c}\text { Gypsum } \\
\text { board }\end{array}$ & 1.23 & 732 & $\begin{array}{l}11 \\
.8 \\
\end{array}$ & $\begin{array}{r}21 \\
.5 \\
\end{array}$ & $\begin{array}{c}10 \\
7 \\
\end{array}$ & 6.8 & 6.8 & 6.8 & $\begin{array}{l}8 . \\
83 \\
\end{array}$ & $\begin{array}{l}4 . \\
84 \\
\end{array}$ & $\begin{array}{l}0 . \\
97 \\
\end{array}$ & $\begin{array}{l}3 . \\
11 \\
\end{array}$ & $\begin{array}{l}4 . \\
20 \\
\end{array}$ & $\begin{array}{r}9 . \\
38 \\
\end{array}$ & $\begin{array}{l}1 . \\
56\end{array}$ & $\begin{array}{l}1 . \\
15 \\
\end{array}$ & $\begin{array}{l}0 . \\
52 \\
\end{array}$ & $\begin{array}{l}0 . \\
79 \\
\end{array}$ & $\begin{array}{l}1 . \\
0\end{array}$ & $\begin{array}{l}1 . \\
0\end{array}$ \\
\hline $\begin{array}{c}\text { Cement } \\
\text { mortar }\end{array}$ & 2.22 & 1910 & $\begin{array}{l}20 \\
.6\end{array}$ & $\begin{array}{l}32 \\
.5\end{array}$ & $\begin{array}{l}70 \\
.6\end{array}$ & $\begin{array}{c}28 . \\
1\end{array}$ & $\begin{array}{c}24 . \\
0\end{array}$ & $\begin{array}{c}12 . \\
5\end{array}$ & $\begin{array}{l}1 . \\
23\end{array}$ & $\begin{array}{l}0 . \\
91\end{array}$ & $\begin{array}{l}0 . \\
80\end{array}$ & $\begin{array}{l}2 . \\
02\end{array}$ & $\begin{array}{l}2 . \\
75\end{array}$ & $\begin{array}{l}5 . \\
61\end{array}$ & $\begin{array}{l}0 . \\
58\end{array}$ & $\begin{array}{c}0 . \\
50\end{array}$ & $\begin{array}{l}0 . \\
47\end{array}$ & $\begin{array}{l}1 . \\
0\end{array}$ & $\begin{array}{l}1 . \\
0\end{array}$ & $\begin{array}{l}1 . \\
0\end{array}$ \\
\hline
\end{tabular}
hygrothermal properties vary with $\mathrm{RH}$. The thickness of samples is thinner than its $\mathrm{d}_{\mathrm{EMPD}}$ during some test conditions (RH 55\%-70\%) for gypsum board, while wider for cement mortar.

Table 1. The Physical Properties of the Materials

\subsection{Standard Test}

\subsubsection{Test condition}

The standard test condition in this study distinguished from that of the MBV test, consisted of two steps that are more realistic of the situations in offices: a constant-rate moisture dissipation step in the day, and a ventilation step at night. The preconditioning condition was $27^{\circ} \mathrm{C} \& 55 \%$. The air temperature kept constant during the test. The experimental period of 24 hours included 8 hours' moisture dissipation, with a constant rate of $5 \mathrm{~g} /\left(\mathrm{h}^{\cdot} \mathrm{m}^{3}\right)$ ) from people without any ventilation, and 16 hours' ventilation, with a constant rate of $0.1 \mathrm{ACH}$ without any moisture dissipation.

\subsubsection{Box Model}

The test box model was built following a real facility prototype as Fig. 3 shows. It is $1.5 \mathrm{~m}$ long, $0.81 \mathrm{~m}$ wide and $0.926 \mathrm{~m}$ high, with a net volume of $1.1 \mathrm{~m}^{3}$ and a sample test area of $1.215 \mathrm{~m}^{2}$. The box was made by the hygroscopic materials, covered by iron sheet outside and aluminum foil inside for being non-hygroscopic. The samples were put on the bottom of the box for testing. The five surfaces of the samples were non-hygroscopic by covering metal foil, and the top surface was exposed to the ambient air in box. 


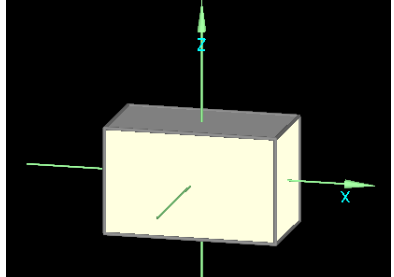

Fig. 3 The Box Model in WUFI-Plus

\subsection{Real Building Test}

\subsubsection{Test Condition}

A similar two-step test condition was set as the real building condition: 8 hours' moisture dissipation with a constant rate of $220 \mathrm{~g} / \mathrm{h}$, and 16 hours' ventilation with a constant rate of $0.2 \mathrm{ACH}$. The indoor $\mathrm{T}$ and $\mathrm{RH}$ were preconditioned as $27^{\circ} \mathrm{C} \& 55 \%$, and the indoor T were kept to be $27^{\circ} \mathrm{C}$ during the test.

\subsubsection{Room Model}

The room model was built following a typical office as Fig. 4 shows. It is a small cube office, with a height of $3 \mathrm{~m}$ and a net volume of $9 \mathrm{~m}^{2}$. The walls $\left(3 \times 3 \times 2 \mathrm{~m}^{2}\right)$ were all finished with mortar cement, and the celling $\left(3 \times 3 \mathrm{~m}^{2}\right)$ was covered by gypsum board. It was assumed that no moisture transferred between the hygroscopic materials and the main structures of the room.

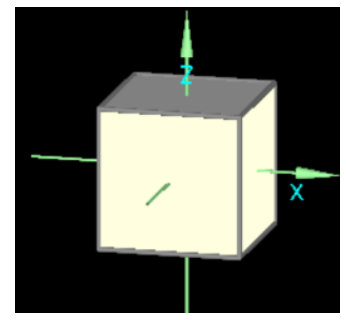

Fig. 4 The Room Model in WUFI-Plus

The real building test was different from the standard one in the aspects of the materials' surface area or area/volume ratio, the moisture dissipation rate, and the ventilation rate.

\subsection{Data Analysis}

The key parameters of $a, b_{m}, \beta_{i}$ in the two EMPD models, and the extra parameters of $t_{p, 2}, t_{p, 3}, \ldots, t_{p, n}$ in the new multilayer model were obtained by analyzing the standard test results with the inverse method. In the method, $\mathrm{P}_{\mathrm{vi}}$ was selected as the criterion and the least square method was adopted to fitting the EMPD model predictions with the test results:

$$
\sum_{i=1}^{n}\left[P_{v i, i}^{\text {model }}-P_{v i, i}^{\text {measured }}\right]^{2}=\min
$$

The prediction performances of the EMPD models in the real building condition were evaluated by the following two indices:

$$
\begin{aligned}
& N R M S E=1-\frac{\left\|P_{v i, i}^{\text {model }}-P_{v i, i}^{\text {measured }}\right\|}{\left\|P_{v i, i}^{\text {model }}-\frac{P_{v i, i}^{\text {model }}}{n}\right\|} \\
& N M S E=1-\frac{\left\|P_{v i, i}^{\text {model }}-P_{v i, i}^{\text {measured }}\right\|^{2}}{\left\|P_{v i, i}^{\text {model }}-\frac{P_{v i, i}^{\text {model }}}{n}\right\|^{2}}
\end{aligned}
$$

Both NRMSE and NMSE cost vary between -Inf (bad fit) to 1 (perfect fit).

The accumulative moisture ab-/desorption amount of the materials are usually weighted by scale in some laboratory tests. It can be written as following:

$$
M G_{b u f}=\sum_{i=1}^{m} G_{b u f, \mathrm{i}} \times h
$$

\section{Results}

\subsection{Forward Solution of the One-layer EMPD Model}

In the EMPD model, the materials' hygrothermal properties that indeed vary with $\mathrm{T}$ and $\mathrm{RH}$ greatly is set as constant. The hygrothermal properties at $55 \%, 70 \%$ and $85 \%$ $\mathrm{RH}$ were therefore chosen, and the forward solutions of the one-layer EMPD model were compared with that of the standard box test results based on the HAM model as shown in Fig. 5. 


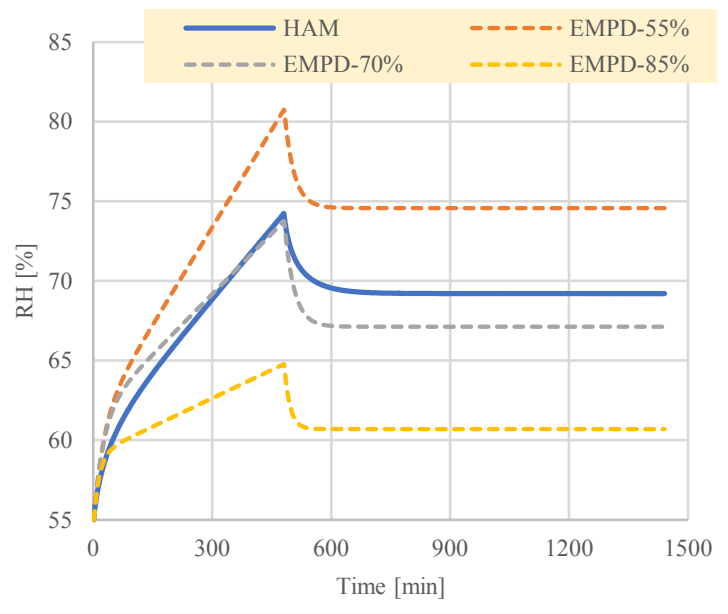

(1) Gypsum Board

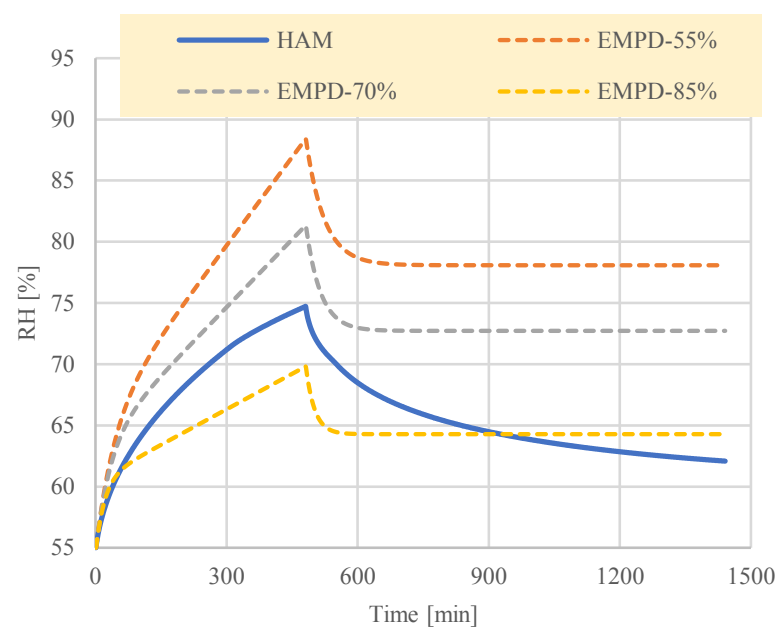

(2) Mortar Cement

Fig. 5 The calculation results of the existing one-layer model with the different hygrothermal properties $(0 \mathrm{ACH}$ at ventilation step

It can be seen that the predictions of the EMPD model varied greatly with the input hygrothermal properties. The prediction with the properties at $70 \% \mathrm{RH}$ was relatively closer to the test results, indicating that the EMPD model is more reliable by using the hygrothermal properties at the middle point of RH variation range in corresponding to the moisture dissipation step. It can be also found that the performance of the EMPD model was quite poor in general. It is worth to notice that in Fig. 5 (2), the test curve decreased smoothly and gradually in the ventilation step, whereas fell rapidly and then flatten out for the EMPD predicted curves. This indicates the problems with the existing EMPD model, especially in the case of materials'

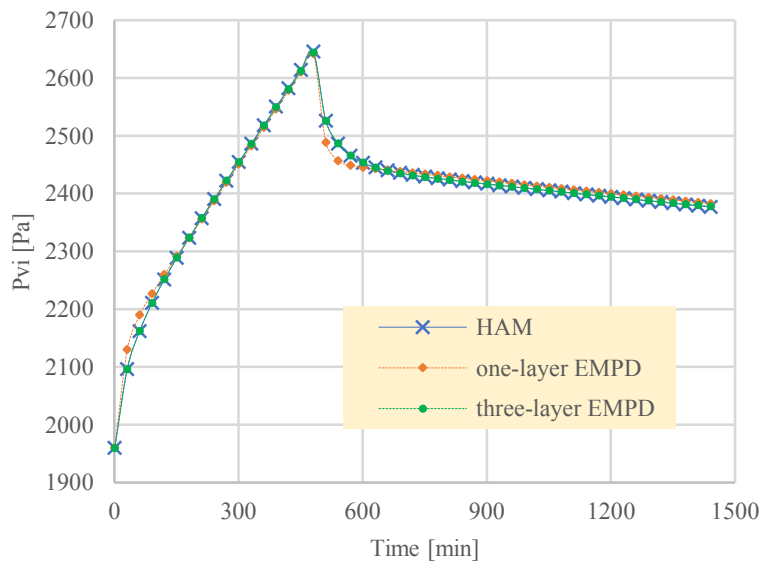

(1) Gypsum Board thickness smaller than its $\mathrm{d}_{\mathrm{EMPD}}$.

\subsection{Inverse Solution of the Two EMPD Models}

The modified three-layer EMPD model is chosen to compare with the existing one-layer EMPD model. The inverse parameters were extracted by fitting the two sets of $\mathrm{P}_{\mathrm{vi}}$ between the HAM model results and the EMPD models results as shown in Fig.6. The extracted inverse parameters through fitting from the lines in Fig. 6 are shown in Table 2.

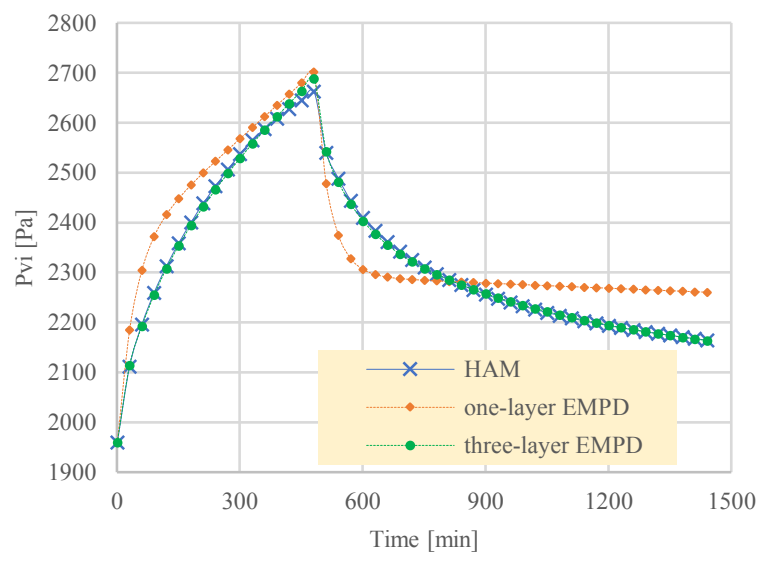

(2) Mortar Cement

Fig. 6 The Fitting results of Pvi from HAM model

Table 2. Inverse Parameters by Fitting

\begin{tabular}{|c|c|c|c|c|c|c|c|c|}
\hline \multirow{2}{*}{ Materials } & \multirow{2}{*}{ EMPD Model } & \multicolumn{5}{|c|}{ Inverse parameters } & \multicolumn{2}{|c|}{ Evaluation Indices } \\
\hline & & $\mathrm{a}$ & $b_{m}\left(\times 10^{-7}\right)$ & $\beta_{i} \quad\left(\times 10^{-8}\right)$ & $t_{p, 2}$ & $t_{p, 3}$ & NRMSE* & NMSE* \\
\hline \multirow{2}{*}{ Gypsum Board } & one-layer & 0.847 & 4.14 & 5.57 & - & - & 0.889 & 0.988 \\
\hline & three-layer & 0.115 & 3.69 & 2.63 & 870583.8 & 1521929.7 & 0.994 & 0.999 \\
\hline \multirow{2}{*}{ Cement Mortar } & one-layer & 1 & 5.18 & 0.43 & - & - & 0.521 & 0.771 \\
\hline & three-layer & 0.319 & 3.01 & 2.95 & 629681.7 & 3823139.7 & 0.961 & 0.999 \\
\hline
\end{tabular}


As shown in Fig.6, the curves of three-layer EMPD model was highly identical with that of HAM model, but not for the curves of one-layer EMPD model. Compared with the curves of HAM model, those of one-layer model increased and declined more rapidly at the start of two steps respectively, and then went smoothly. Especially, in the cases of mortar cement, the calculation of one-layer model didn't converge. It confirmed the previous hypothesis where the existing one-layer EMPD model is limited in some scenario. That is, it may be acceptable to those samples whose thickness are thinner than their $\mathrm{d}_{\mathrm{EMPD}}$, but not for the others. For the daily moisture fluctuation, the deep layer may absorb the moisture from the surface layer all the time. In Table 2, the extracted $b_{m}$ and $\beta_{i}$ of the modified EMPD model were also identified to the real values, and both $a$ and $T_{p, i}$ represent the resistance coefficient associated with the cycling period well in the modified model, so NRMSE and NMSE of the modified model results have been significantly improved compared with that of one-layer EMPD model.

Afterwards, the other output parameters (indoor $\mathrm{RH}, \mathrm{G}_{\mathrm{buf}}$, $\mathrm{MG}_{\mathrm{buf}}$ and $\mathrm{P}_{\mathrm{vb}, \mathrm{i}}$ ) were calculated by the inverse parameters.

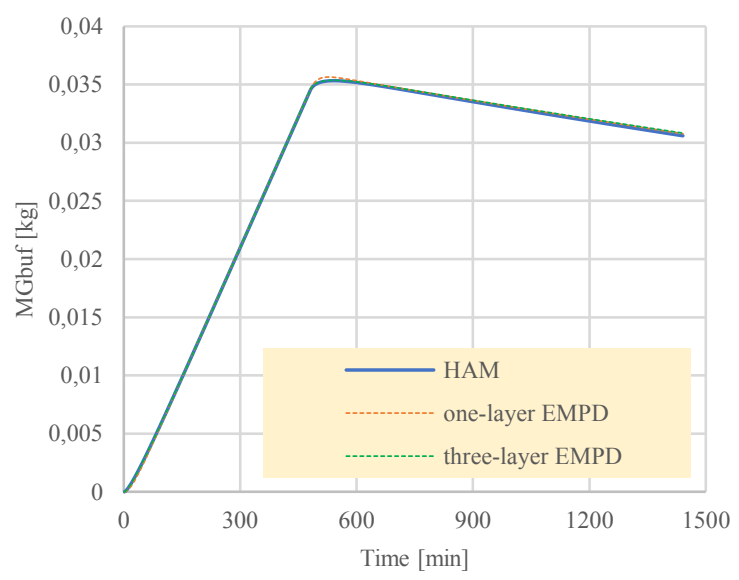

(1) Gypsum Board

Fig.7 The MGbuf results of HAM model and two EMPD models

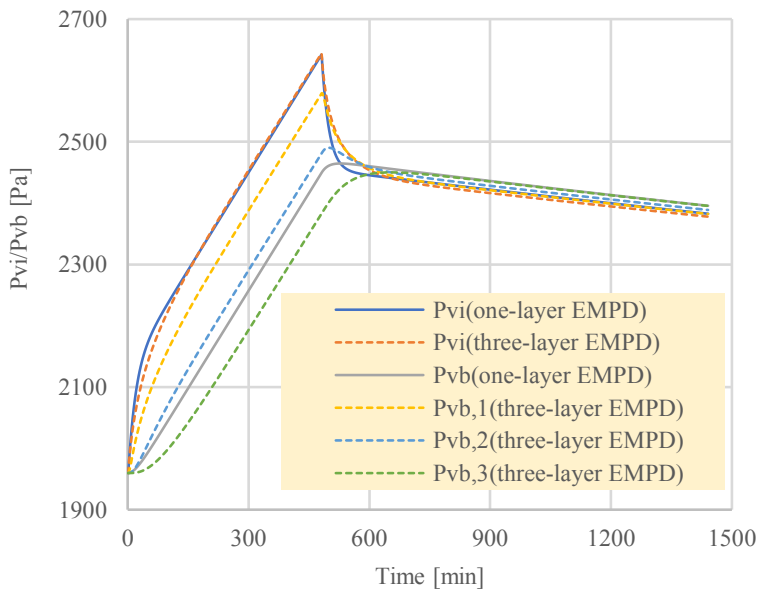

(1) Gypsum Board
The compared curves of $\mathrm{MG}_{\text {buf }}$ between HAM models and two EMPD models are shown as Fig.7, and partial water vapor pressure $\left(\mathrm{P}_{\mathrm{vb}, \mathrm{i}}\right.$ and $\left.\mathrm{P}_{\mathrm{vi}}\right)$ of two EMPD models are shown as Fig.8.

It is obviously that the curves were all close for the two materials cases, and the curves of the three-layer EMPD model corresponds to those of HAM model better. But It would not be ignored that the small deviations of $\mathrm{MG}_{\mathrm{buf}}$ can still cause great change in $\mathrm{P}_{\mathrm{vi}}$ as shown in Fig.7. It can be found that phase difference and the trend of decreasing peak happened in water vapour pressure from air to materials layer-layer in Fig.8. It came with the fact that water vapor transferred from outside to inside of the materials. Besides, in the mortar cement case, the Pvb, 3 increased slightly during the whole period, which means the deep layers of the materials absorb moisture all the time without desorption step. And the $\mathrm{P}_{\mathrm{vb}}$ curve of the one-layer model draw near to the $\mathrm{P}_{\mathrm{vb}, 2}$ curve of the three-layer model. It is illustrated that $\mathrm{P}_{\mathrm{vb}}$ represents average water vapor pressure of the material in one-layer model, and it exaggerates the adsorption speed of the materials in the existing EMPD model.

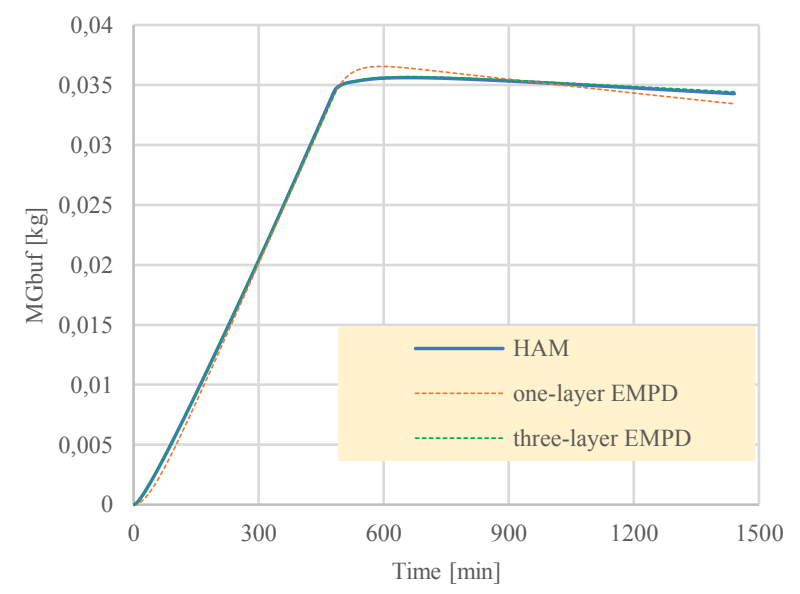

(2) Mortar Cement

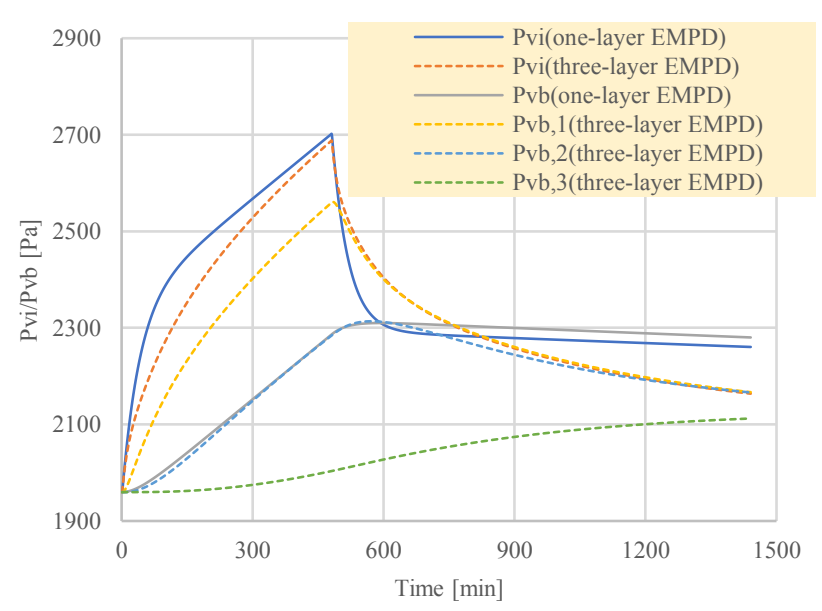

(2) Mortar Cement

Fig.8 Water Vapor Partial Pressure of the Two EMPD Models 


\subsection{Prediction and Verification}

In the previous sections, the modified multilayer EMPD model was presented to be in agreement with the results of HAM model for two materials with diverse hygric properties in the fitting calculation. This section further proves the verification of the two EMPD models by predicting the indoor $\mathrm{RH}$ of a new room case using the inverse parameters extracted by the standard box test.

Fig. 9 shows the compared curves between the predicted results of two EMPD models and the simulation results of HAM model.

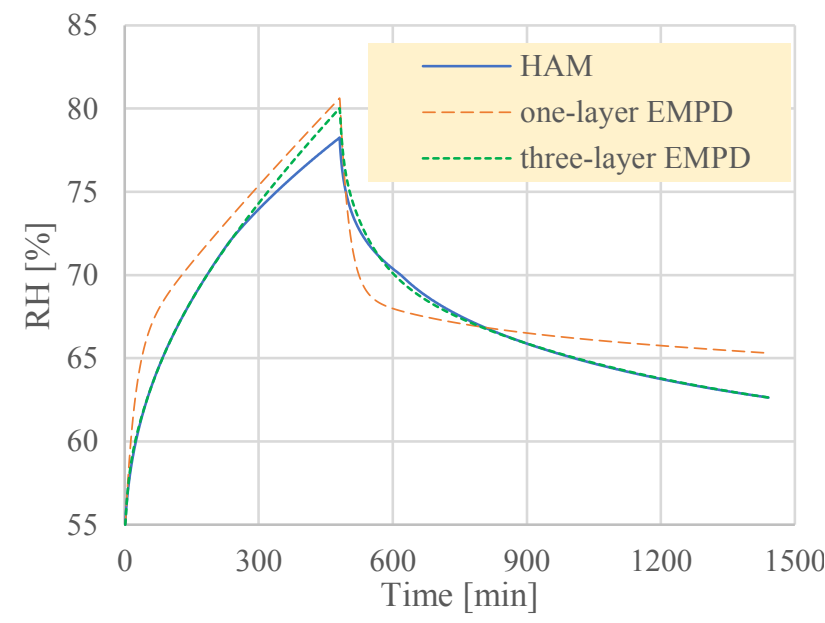

Fig.9 Predicting RH of the Room Based on the Extract Inverse Parameters

The prediction RH maxima of two EMPD models were approximately $2 \% \mathrm{RH}$ higher than one of HAM model. As shown in the curve of the modified EMPD model, the RH was overestimated at the start of $73 \% \mathrm{RH}$ point in the moisture dissipation step. It was indicated that $b_{m}$ of the materials increase with the RH, but it didn't influence the tendency. The two RH curves between the HAM model and the three-layer EMPD model are pretty close, but the RH curve of one-layer model deviates greatly. The same conclusion can be drawn as in the previous section: the existing one-layer model is not able to predict the exact course of the RH. It appears that the estimation of the modified multilayer EMPD model is reliable.

\section{Conclusion}

Moisture is a significant factor for inhabitant life in buildings. It is necessary to determine and utilize adequately the moisture buffer potential of the materials. However, due to the existing limited model and insufficient database, it is hard to implement in applications for moisture design and prediction.

Therefore, this research proposed a fast and simple approach to identify and predict the moisture performances of building materials. Main contribution of this research is as following:

- The existing one-layer EMPD model is found to have limited in specific occasion, for that, the modified multilayer EMPD model is proposed.
- The corresponding experimental protocol is presented The key parameters of the EMPD model can be inversed based on the only $24 \mathrm{~h}$ box standard test.

- $\quad$ The modified multilayer EMPD model is verified to have reliable results for $\mathrm{RH}$ prediction in various broader conditions.

This research relies on some strong assumptions. First, the material is isothermal, which is suitable for the airconditioned room or equable temperature region. Second, moisture transferring through the envelope is ignored. Third, the sorption isotherm and water vapor permeability of the materials are considered as constant value in the measured relative humidity interval.

\section{Reference}

1. M. D, F.W. J, Ind Air 17, 9 ( 2010)

2. S. Vesper, C. Barnes, C.E. Ciaccio, A. Johanns, K. Kennedy, J.S. Murphy, A. Nunez-Alvarez, M.T. Sandel, D. Cox, G. Dewalt, P.J. Ashley, J Asthma 50, 7 (2013)

3. A. Cheng, Y. Hsin, W.-T. Lin, KSCE J Civ Eng 18, 8 (2014)

4. F. L, C. G, F.P. O, Ind Air 9, 8 (2010)

5. P.A. L, K.J. P, R. S, Int Biod \& Biod 42, 11 (2000)

6. S. Yu, Y. Cui, Y. Shao, F. Han, Energ 12, 17 (2019)

7. C. Rode, Department of Civil Engineering, Technical University of Denmark, 2005.

8. H. Janssen, S. Roels, Ener Build 41 (2009) 13.

9. P. T, J.L. A, 9th Nordic Symposium on Building, (2011)

10. H. M.Kunzel, Fraunhofer Institute of Building Physics (1995)

11. D.o. Energy, Energyplus V8.9.0 Engineering

Reference, (2018)

12. M.J. Cunningham, Build Environ 27, 7 (1992)

13. M. Steeman, A. Janssens, H.J. Steeman, M. Van Belleghem, M. De Paepe, Build Environ 45, 12 (2010)

14. M.K. Kumaran, J.C. Lackey, N. Normandin, F. Tariku, D.v. Reenen, National Research Council, Canada, (2002)

15. M.K. Kumaran, IEA ANNEX 24, International Energy Agency (1996)

16. F. C, J. H, F. Y, Build Environ 85, 13 ( 2015)

17. J. Woods, J. Winkler, Ener Build 117, 8 (2016)

18. J. Woods, J. Winkler, Ener Build 165, 16 (2018)

19. E. Vereecken, S. Roels, H. Janssen, J Build Phys 34, 24 (2010)

See Nomenclature Appendix 1. Appendix 1 on the next page. 
Appendix 1

\begin{tabular}{|c|c|c|c|c|c|}
\hline \multicolumn{6}{|c|}{ Nomenclature } \\
\hline$P_{v i}$ & $\begin{array}{c}\text { the partial vapour pressure of interior } \\
\text { air }\end{array}$ & $\mathrm{Pa}$ & $h$ & time step & $\mathrm{S}$ \\
\hline$P_{v e}$ & $\begin{array}{c}\text { the partial vapour pressure of } \\
\text { interior/exterior air }\end{array}$ & $\mathrm{Pa}$ & $m$ & calculation time & - \\
\hline $\mathrm{n}$ & the air change rate per hour & $1 / \mathrm{h}$ & $\mathrm{P}_{v b, i}$ & $\begin{array}{c}\text { the average vapor pressure in } \\
\text { the center of the i-th humidify } \\
\text { buffering layer }\end{array}$ & $\mathrm{Pa}$ \\
\hline $\mathrm{V}$ & the volume of the zone & $\mathrm{m}^{3}$ & $\theta_{b}$ & $\begin{array}{c}\text { the average temperature in the } \\
\text { center of the humidify buffering } \\
\text { layer }\end{array}$ & $\mathrm{K}$ \\
\hline$R_{v}$ & $(=462)$ the gas constant of water vapor & $\mathrm{J} / \mathrm{kg} / \mathrm{K}$ & $d_{b, i}$ & $\begin{array}{l}\text { the thickness of the } \mathrm{i} \text {-th } \\
\text { buffering layer }\end{array}$ & $\mathrm{m}$ \\
\hline$T_{i}$ & the interior air temperature & $\mathrm{K}$ & $\delta_{p}$ & the water vapor permeability & s \\
\hline$A$ & the area of the material & $\mathrm{m}^{2}$ & $\xi$ & the moisture capacity & $\mathrm{kg} / \mathrm{m}^{3}$ \\
\hline$G_{v p}$ & the interior vapor production & $\mathrm{kg} / \mathrm{s}$ & $t_{p, i}$ & $\begin{array}{l}\text { the coefficient associated with } \\
\text { the cycling time in the i-th layer }\end{array}$ & $\mathrm{s}$ \\
\hline $\mathrm{G}_{b u f}$ & $\begin{array}{l}\text { the moisture exchange between room } \\
\text { air and room enclosure }\end{array}$ & $\mathrm{kg} / \mathrm{s}$ & $P_{\text {sat }}$ & the saturated vapor pressure & $\mathrm{Pa}$ \\
\hline $\mathrm{MG}_{b u f}$ & $\begin{array}{l}\text { the accumulative moisture ab- } \\
\text { /desorption amount of the materials }\end{array}$ & $\mathrm{kg}$ & $\beta_{i}$ & $\begin{array}{l}\text { the convective surface film } \\
\text { coefficient }\end{array}$ & $\mathrm{s} / \mathrm{m}$ \\
\hline NRMSE & normalized root mean squared error & - & NMSE & normalized mean squared error & - \\
\hline
\end{tabular}

